\section{Medical marijuana revisited}

Fletcher concludes in his CMAJ editorial that because cannabis has not been through the regulatory approval processes required of pharmaceutical medications, doctors should not "be lulled into prescribing" medical marijuana.

Currently, cannabis is commonly used in the treatment of many medical conditions. Health Canada's "Category 1" and "Category 2" conditions include multiple sclerosis, HIV/AIDS, epilepsy, cancer, severe arthritis, spinal cord disease/injury, Crohn colitis, fibromyalgia, migraines, posttraumatic stress disorder, and many others. ${ }^{2}$

With Health Canada predicting 400000 Canadians will be using medical cannabis over the next decade, ${ }^{3}$ more Canadian physicians will need to respond to the growing therapeutic need.

As a palliative care physician, I have patients desperately asking me for legal access to medical marijuana to help control pain, improve appetite, reduce nausea, increase energy and reduce insomnia and anxiety. Patients deserve safe and legal access to this ancient herbal treatment without the fear of criminal sanctions.

Physicians do need to be better educated about the dose-response effects and risk-benefit profiles of various cannabis products over and above the currently available pharmaceutical THC (delta-9-tetrahydrocannabinol) options (i.e., Cesamet [nabilone]). However, I believe that physicians should not be dissuaded from authorizing their patients to obtain legal access to medical cannabis.

Across Canada, there are medical cannabis dispensaries known as compassion clubs that are already providing patients with access to high-quality cannabis products. Under the proposed new Marihuana for Medical Purposes Regulations, ${ }^{4}$ dispensaries will be required to further test their products for cannabinoid levels and contaminants, which will standardize and secure the process even more. This will undoubtedly improve the quality of life of many patients with chronic disease. ${ }^{5}$

\section{Michael A. Dworkind MD}

Associate Professor of Family Medicine, McGill University, Montréal, Que.

\section{References}

1. Fletcher J. Marijuana is not a prescription medicine. CMAJ 2013;185:369.

2. Health Canada MMAR Application Form B1. Ottawa (ON): Health Canada; 2007. Available: http://medicalmarijuana.ca/for-patients/health-canada -forms (accessed 2013 Apr. 22)

3. Marihuana for medical purposes regulations: regulatory impact analysis statement. Ottawa $(\mathrm{ON})$ : Health Canada; 2012. Available: http://gazette.gc.ca/rp-pr /p1/2012/2012-12-15/html/reg4-eng.html (accessed 2013 Apr. 22)

4. Marihuana for Medical Purposes Regulations. Canada Gazette [Ottawa, ON]. 2012 Dec. 15. Available: http://gazette.gc.ca/rp-pr/p1/2012/2012-12-15 $/ \mathrm{html} / \mathrm{reg} 4$-eng.html (accessed 2013 Apr. 22).

5. Inclusion of medical cannabis dispensaries in the regulatory framework. Ottawa (ON): Canadian Association of Medical Cannabis Dispensaries; 2011. Available: www.camcd- acdcm.ca/wp-content /uploads/CAMCDSubmissionJuly2011.pdf

CMAJ 2013. DOI:10.1503/cmaj.113-2128

\section{Memories of Dr. Joseph Roach}

Seeing Dr. Roach mentioned in the $C M A J$ was wonderful. ${ }^{1}$

I was lucky enough to interact with him numerous times - when I was a medical student in Cape Breton, Nova Scotia, in the mid-90s and over a few years of my early career, just before he retired.

Dr. Roach had an incredible commitment to his community and to the profession of medicine. He was always a gentleman, and treated everyone with the same respect regardless of their position in life. His capacity for remembering his patients, their medical histories, drug regimens, family histories and relationships was incredible, even into his late years. His kindness, commitment and generosity are things we can all aspire to, even though very few of us will likely ever achieve anything close.

Christopher R. Milburn MSc MD

Physician, Cape Breton District Health Authority, Sydney, NS

\section{Reference}

1. McAlister C. The old country doctor. CMAJ 2013;185:985-6.

CMAJ 2013. DOI:10.1503/cmaj.113-2129

\section{Letters to the editor}

In submitting a letter, you automatically consent to have it appear online and/or in print. All letters accepted for print will be edited by $C M A J$ for space and style. Most references and multiple authors' names, full affiliations and competing interests will appear online only. (The full version of any letter accepted for print will be posted at cmaj.ca.)

\title{
Correction
}

\section{Clinical guidelines}

In the clinical practice guidelines on screening for depression in adults, which appeared in the June 11 print issue of $C M A J,{ }^{1}$ the citations for the 5 studies identified in the systematic review were not included in the reference list and are provided here. ${ }^{2-6}$ The studies were cited as references 19-23 in the text where Table 1 is first mentioned under Recommendations and in Table 1 itself. The remaining references are cited correctly in the text. A revised version of the guidelines is available at www.cmaj.ca/content/185/9/775/suppl/DC3.

\section{References}

1. Canadian Task Force on Preventive Health Care. Recommendations on screening for depression in adults. CMAJ 2013; 185:775-82.

2. Oyama H, Koida J, Sakashita T, et al. Community-based prevention for suicide in elderly by depression screening and follow-up. Community Ment Health J 2004;40:249-63.

3. Oyama H, Fujita M, Goto M, et al. Outcomes of community-based screening for depression and suicide prevention among Japanese elders. Gerontologist 2006;46:821-6.

4. Oyama H, Goto M, Fujita M, et al. Preventing elderly suicide through primary care by community-based screening for depression in rural Japan. Crisis 2006;27:58-65.

5. Oyama $\mathrm{H}$, Ono $\mathrm{Y}$, Watanabe $\mathrm{N}$, et al. Local community intervention through depression screening and group activity for elderly suicide prevention. Psychiatry Clin Neurosci 2006;60:110-4.

6. Oyama H, Sakashita T, Hojo K, et al. A community-based survey and screening for depression in the elderly: the short-term effect on suicide risk in Japan. Crisis 2010;31:100-8.

CMAJ 2013. DOI:10.1503/cmaj.113-2130 